\title{
Pre- and Post-home Visit Behaviors using an after- hours House Call (AHHC) Medical Services: A Questionnaire-based Survey in Tokyo, Japan
}

Ryota INOKUCHI ( $\square$ intensivecareunits@gmail.com )

University of Tsukuba

\section{Kojiro MORITA}

University of Tsukuba

Xueying JIN

University of Tsukuba

Masatoshi ISHIKAWA

University of Tsukuba

Nanako TAMIYA

University of Tsukuba

\section{Research Article}

Keywords: After-hours primary care, Quality, Triage, Severity, AHHC, out-of-hour service, out-of-hours services, $\mathrm{OOH}$, emergency department, ED

Posted Date: March 1st, 2021

DOI: https://doi.org/10.21203/rs.3.rs-253637/v1

License: (우 (i) This work is licensed under a Creative Commons Attribution 4.0 International License. Read Full License

Version of Record: A version of this preprint was published at BMC Emergency Medicine on December 1st, 2021. See the published version at https://doi.org/10.1186/s12873-021-00545-w. 


\section{Abstract}

Background: To reduce the burden caused by emergency department (ED) visits and ambulance use, after-hours house call (AHHC) medical services have been implemented. Examining the pre-and post-home visit behaviors of those who use AHHC medical services, stratified by age and illness severity, may help determine the populations these services should target effectively to reduce ED visits and ambulance use.

Methods: This questionnaire-based study used data from anonymized medical records and internet-based questionnaires completed by patients who used AHHC medical services in Tokyo, Japan, between January 1 and December 31, 2019. The questionnaire consisted of two questions: what action would the patient have taken in the absence of AHHC services, and what action was taken within three days following the use of the AHHC services.

Results: Of the 15,787 patients who used AHHC medical services during the study period, 2,128 completed the questionnaire (13.5\% response rate). Individuals aged $<15$ years and $16-64$ years were the most common users of AHHC services ( $\leq 15$ years, $71.4 \% ; 16-64$ years, $26.8 \%$ ). Before using the AHHC service, the majority of patients in each patient age group would have visited the ED if the AHHC service had not been available ( $\leq 15$ years, $47.8 \%$; $16-64$ years, $42.8 \%$; $\geq 65$ years, $43.6 \%$ ), and the proportion of patients originally planning to call an ambulance was higher among those in higher age groups ( $\leq 15$ years, $1.1 \%$; $16-64$ years, $6.0 \%$; $\geq 65$ years, $20.5 \%)$. After using AHHC services, the majority of patients (68.1\%) did not visit a hospital within three days, but the proportion of patients who visited an ED and called an ambulance within that time increased as their illness severity increased.

Conclusions: Increasing AHHC medical services awareness among older adults and encouraging repeated use of AHHC services for patients with severe illnesses may help reduce ED visits and ambulance use.

\section{Background}

Non-urgent emergency department (ED) visits and ambulance calls are now global issues [1]. ED crowding and increased transport times have not only led to patients being disadvantaged but also increased the burden on health care providers [2]. Recently, several countries have developed after-hours house call (AHHC) medical services or out-of-hours services $(\mathrm{OOH})$ to solve the problems of excessive ED visits and ambulance use [3]. Under the AHHC services, physicians visit patients in their houses after hours, thereby reducing the number of ambulance dispatches and ED visits [4-8].

In Japan, to reduce non-urgent ED visits and ambulance use, telephone consultation services and educational activities to promote appropriate ambulance use were introduced in 2007 [9]; regardless, the number of ambulance calls and the duration of transportation have continued to increase [10]. As part of Japan's universal health care system, patients with emergency health problems can call an ambulance free of charge, and $97.9 \%$ of callers receive ambulance transportation to emergency hospitals [11]. Recently, charging for the ambulance services has been considered [12], but an acceptable solution has not yet been implemented.

In 2016, a private AHHC service was established in Tokyo, Japan. This AHHC service provides consultations and triages via telephone to patients needing medical attention after regular hospital visiting hours. Subsequently, the number of companies offering similar services has been increasing. 
Examining the pre-and post-home visit behaviors of those who use AHHC medical services, stratified by age and illness severity, could help identify the population(s) these services should target to reduce ED visits and ambulance use. However, previous studies have not examined the impact of AHHC service use by age and disease severity. Thus, we investigated these behaviors in patients using Tokyo's AHHC medical service by using patient data and patient-completed questionnaires.

\section{Methods}

This study used data obtained from anonymized medical records and internet-based questionnaires which were completed by patients who used AHHC medical services between January 1 and December 31, 2019. The study was reviewed and approved by the Research Ethics Committee of the University of Tsukuba (approval number, 1527).

\section{Data Sources}

In this study, the anonymized clinical records of all patients who had used the AHHC services during the study period were reviewed, along with the questionnaires completed by them. Information regarding patient sex, age, and illness severity were extracted from the medical records. The questionnaire consisted of two questions: what action would the patient have taken in the absence of AHHC services (stay home, wait for consultation until a hospital opens, visit ED, or call an ambulance) and what action was taken within three days following the use of the AHHC services (no hospital visit, visited an outpatient clinic, visited an ED, received another house call, or called an ambulance) (Supplemental File).

\section{Japan's Health Care System}

Emergency hospitals in Japan are categorized as primary, secondary, or tertiary [13]. Generally, for primary care, holiday and night-time EDs are available for non-severe conditions. Secondary hospitals provide emergency first aid for patients and, if necessary, inpatient care. Tertiary hospitals provide tertiary emergency medical and advanced critical care $[14,15]$.

Under Japan's universal health care system, ambulatory patients have free access to any hospital facility, regardless of their symptoms [16]. This is because Japan has not established a general practitioner system, like in Europe. Furthermore, anyone can call an ambulance service, without any expenditure [17]. If an ambulance is called, patients are transported to a secondary or tertiary hospital, depending on the severity of their condition.

\section{AHHC Medical Services in Japan}

A private AHHC medical service (Fast Doctors, Shinjuku, Tokyo, Japan), covered by Japan's universal health care system, has been operating in Tokyo since 2016. Patients can access the service via direct phone call, or can request a consultation online. The company operates seven days/week outside of regular hospital visiting hours (i.e., 19:00-06:00 on weekdays, 18:00-06:00 on Saturdays, and 24 hours/day on Sundays and holidays). The AHHC services have about 4-12 doctors/shift. 
Following a telephone triage, instead of sending an ambulance, the service sends a doctor directly to the patient's residence. The telephone triage involves a patient calling an emergency telephone consultation service and being classified into one of five categories (red, orange, yellow, green, or white), based on symptom acuity. The red category implies the presence of a life-threatening condition or one that is likely to worsen or change rapidly; orange reflects a condition requiring immediate hospital attendance, as the symptom(s) may worsen over time; yellow requires a hospital visit as the symptom(s) may worsen over time; green does not have symptoms listed in the previous categories but requires a hospital visit; and white reflects symptoms that do not require a hospital visit [9].

After the telephone triage, the AHHC service doctors perform home visits for patients classified as orange and yellow. Following the consultation, the doctor assesses the illness severity (mild, moderate, or severe); mild illnesses are those that can be treated using over-the-counter medications, moderate illnesses require the patient to visit a hospital or clinic, and severe illnesses require ambulance transportation.

\section{Statistical Analysis}

We compared the patient characteristics (age, sex, and illness severity) between questionnaire responders and non-responders. As appropriate, Pearson's chi-square test or Fisher's exact test were used to compare categorical variables, and Student's t-test or the Wilcoxon-Mann-Whitney test were used to compare continuous variables. Analyses were performed using JMP 14.3 statistical software (SAS Institute, Cary, NC, USA) and a value of $p<$ 0.05 was considered statistically significant.

\section{Results}

Of the 16,067 patients who received AHHC medical services during the study period, we excluded 280 owing to missing responses. Of the remaining 15,787 patients, 2,128 returned completed questionnaires (13.5\% response rate).

\section{Characteristics of Responders and Non-Responders}

Patients who completed the questionnaires were younger than the non-responders (6 years [IQR 2, 25] vs. 7 years [IQR 2, 30], $p<0.001$ ) and had less severe symptoms than the non-responders ( $p=0.012)$ (Table 1). Patients $\leq 15$ years and those 16-64 years were the most common users of the AHHC service. There were no differences in sex ratio between the age groups. 
Table 1

Characteristics of responder and non-responder patients

\begin{tabular}{|llll|}
\hline & $\begin{array}{l}\text { Responders } \\
(\mathrm{N}=2128)\end{array}$ & $\begin{array}{c}\text { Non-responders } \\
(\mathrm{N}=13,659)\end{array}$ & p-value \\
\hline Age (years), median [IQR] & $6[2,25]$ & $7[2,30]$ & $<0.001$ \\
\hline Age group, $\mathrm{N}(\%)$ & & & \\
\hline & & & \\
\hline$\leq 15$ years & & & \\
\hline $16-64$ years & $1519(71.4)$ & $8237(60.3)$ & \\
\hline$\geq 65$ years & $570(26.8)$ & $5159(37.8)$ & 0.67 \\
\hline Sex & $39(1.8)$ & $263(1.9)$ & \\
\hline Male (\%) & & & \\
\hline Severity (\%) & $1014(47.7)$ & $6578(48.2)$ & \\
\hline Mild & & & \\
\hline Moderate & & & \\
\hline Severe & & & \\
\hline IQR, interquartile range & & & \\
\hline
\end{tabular}

\section{Probable Actions in the Unavailability of AHHC Service}

The proportion of patients originally planning to call an ambulance was $46.4 \%$. In each age group, the majority of patients reported visiting EDs because AHHC services were not available ( $\leq 15$ years, 47.8\%; 16-64 years, $42.8 \%$; $\geq 65$ years, $43.6 \%$ ). Table 2 also indicates that as the age group increased, the proportion of patients who would have called an ambulance also increased ( $\leq 15$ years, 1.1\%; $16-64$ years, 6.0\%; $\geq 65$ years, $20.5 \%$ ).

When stratified by illness severity (Table 2), the proportion of those who had planned to call an ambulance increased with increasing illness severity (mild, 2.1\%; moderate, 30.2\%; severe, $40.0 \%$ ), while the proportion of those who had planned to stay home decreased with increasing illness severity (mild, 54.7\%; moderate, 45.8\%; severe, 10.0\%). There was no significant difference of action between sexes $(p=0.14)$. 
Table 2

Actions taken if the after-hours house call (AHHC) services had been unavailable

\begin{tabular}{|c|c|c|c|c|}
\hline & $\begin{array}{l}\text { Stayed } \\
\text { home }\end{array}$ & $\begin{array}{l}\text { Waited for a consultation } \\
\text { until a hospital } \\
\text { opened }\end{array}$ & $\begin{array}{l}\text { Visited the emergency } \\
\text { department }\end{array}$ & $\begin{array}{l}\text { Called an } \\
\text { ambulance }\end{array}$ \\
\hline $\begin{array}{l}\text { All patients, N } \\
(\%)\end{array}$ & $\begin{array}{l}208 \\
(9.8)\end{array}$ & 875 (41.1) & 987 (46.4) & $58(2.7)$ \\
\hline \multicolumn{5}{|l|}{ Age group } \\
\hline $\begin{array}{l}\leq 15 \text { years }(\mathrm{N}= \\
1519)\end{array}$ & $\begin{array}{l}132 \\
(8.7)\end{array}$ & 645 (42.5) & 726 (47.8) & $16(1.1)$ \\
\hline $\begin{aligned} & 16-64 \text { years }(\mathrm{N} \\
= & 570)\end{aligned}$ & $\begin{array}{l}73 \\
(12.8)\end{array}$ & $219(38.4)$ & 244 (42.8) & $34(6.0)$ \\
\hline 39) $\geq 65$ years $(N=$ & $3(7.7)$ & $11(28.2)$ & $17(43.6)$ & $8(20.5)$ \\
\hline \multicolumn{5}{|l|}{ Severity } \\
\hline Mild ( $N=1253)$ & $\begin{array}{l}143 \\
(11.4)\end{array}$ & $543(43.3)$ & $541(43.2)$ & $26(2.1)$ \\
\hline $\begin{array}{l}\text { Moderate }(\mathrm{N}= \\
865)\end{array}$ & $65(7.5)$ & 331 (38.3) & $441(51.0)$ & $28(3.2)$ \\
\hline Severe $(N=10)$ & $0(0)$ & $1(10.0)$ & $5(50.0)$ & $4(40.0)$ \\
\hline
\end{tabular}

\section{Behavior Within Three Days of using AHHC Service}

The 2,128 patients who provided answers indicated that, within three days of using the AHC service, most did not visit a hospital (68.3\%); however, some visited an outpatient clinic (27.0\%) or an ED (2.8\%), and some used daily home-visits $(1.0 \%)$ or called an ambulance $(0.8 \%)$ (Table 3$)$. 
Table 3

Patient actions during the three days following the use of the after-hours house call service (AHHC), based on both the expected initial action if the service had not been available and on illness severity.

\begin{tabular}{|c|c|c|c|c|c|c|}
\hline & & \multicolumn{5}{|c|}{ After using the $\mathrm{AHHC}$ service } \\
\hline & & $\begin{array}{l}\text { Did not } \\
\text { visit a } \\
\text { hospital }\end{array}$ & $\begin{array}{l}\text { Visited an } \\
\text { outpatient } \\
\text { clinic }\end{array}$ & $\begin{array}{l}\text { Used a } \\
\text { daily } \\
\text { home- } \\
\text { visit }\end{array}$ & $\begin{array}{l}\text { Visited an } \\
\text { emergency } \\
\text { department }\end{array}$ & $\begin{array}{l}\text { Called an } \\
\text { ambulance }\end{array}$ \\
\hline \multirow{5}{*}{$\begin{array}{l}\text { Expected } \\
\text { response before } \\
\text { using the AHHC } \\
\text { service }\end{array}$} & All (N = 2128) & $\begin{array}{l}1453 \\
(68.3)\end{array}$ & $\begin{array}{l}575 \\
(27.0)\end{array}$ & $\begin{array}{l}60 \\
(2.8)\end{array}$ & $22(1.0)$ & $18(0.8)$ \\
\hline & $\begin{array}{l}\text { Remained at home } \\
(N=208)\end{array}$ & $\begin{array}{l}158 \\
(76.0)\end{array}$ & $39(18.8)$ & $3(1.4)$ & $6(2.9)$ & $2(1.0)$ \\
\hline & $\begin{array}{l}\text { Waited for a } \\
\text { consultation until a } \\
\text { hospital opened }(\mathrm{N}= \\
875)\end{array}$ & $\begin{array}{l}602 \\
(68.8)\end{array}$ & $\begin{array}{l}250 \\
(28.6)\end{array}$ & $9(1.0)$ & $10(1.1)$ & $4(0.5)$ \\
\hline & $\begin{array}{l}\text { Visited an } \\
\text { emergency } \\
\text { department }(\mathrm{N}=987)\end{array}$ & $\begin{array}{l}662 \\
(67.1)\end{array}$ & $\begin{array}{l}270 \\
(27.4)\end{array}$ & $7(0.7)$ & $41(4.2)$ & $7(0.7)$ \\
\hline & $\begin{array}{l}\text { Called an } \\
\text { ambulance }(\mathrm{N}=58)\end{array}$ & $\begin{array}{l}31 \\
(53.4)\end{array}$ & $16(27.6)$ & $3(5.2)$ & $3(5.2)$ & $5(8.6)$ \\
\hline \multirow[t]{3}{*}{ Illness severity } & Mild $(N=1253)$ & $\begin{array}{l}853 \\
(68.1)\end{array}$ & $\begin{array}{l}355 \\
(28.3)\end{array}$ & $\begin{array}{l}10 \\
(0.8)\end{array}$ & $26(2.1)$ & $9(0.7)$ \\
\hline & Moderate ( $\mathrm{N}=865)$ & $\begin{array}{l}598 \\
(69.1)\end{array}$ & $\begin{array}{l}218 \\
(25.2)\end{array}$ & $\begin{array}{l}11 \\
(1.3)\end{array}$ & $32(3.7)$ & $6(0.7)$ \\
\hline & Severe $(N=10)$ & $2(20.0)$ & $2(20.0)$ & $\begin{array}{l}1 \\
(10.0)\end{array}$ & $2(20.0)$ & $3(30.0)$ \\
\hline
\end{tabular}

When stratified by their intended action before using the AHHC service, the proportion of patients who did not visit hospitals within three days of their $\mathrm{AHHC}$ visit decreased in the following order: staying at home (76.0\%), waiting for a consultation (68.8\%), visiting an ED (67.1\%), or calling an ambulance (53.4\%). Further, when stratified by illness severity, the proportions of patients with severe illnesses who visited EDs (20.0\%) or called ambulances (30.0\%) within the three-day period were similar or higher.

\section{Discussion}

The present study found that 1) the proportion of patients who had originally planned to visit an ED was $>40 \%$ in each age group, 2) the proportion of patients who had originally planned to call an ambulance increased with patient age, and 3) the proportion of those who visited an ED or called an ambulance within three days of using the AHHC service were low; however, the proportion of patients who visited an ED or called an ambulance within that time increased as their illness severity increased.

Although several papers have reported analyses of patient factors or behaviors leading to the call for an ambulance, this is the first to describe patient behaviors before and after using the AHHC medical services 


\section{Probable Patient Actions in the Absence of AHHC Service}

The present study showed that $46.4 \%$ of respondents would have visited an ED if the AHHC service had not been available. This result is similar to the $43 \%$ reported in a Dutch study [18] and the $40.1 \%$ reported in an Australian study [19]. Additionally, we found that after using the AHHC service, majority of the responding patients (68.1\%) reported not visiting a hospital within the following three days; $2.8 \%$ visited an ED and $0.9 \%$ called an ambulance within that time period. Similarly, an Australian study showed that, after an AHHC visit, $40 \%$ of patients did not require a follow-up and $8.4 \%$ of patients visited an ED [19]. Other studies have also reported declines in ED visits following the introduction of the AHHC services [20-23]. These findings indicate that AHHC services have reduced the number of ED visits and the number of ambulance calls.

\section{Patient Age and Ambulance Calling Plans}

We found that the proportion of those who had planned to call ambulances, prior to contacting AHHC service personnel, increased with age. Previous national and international studies have shown that older adults are more likely to call an ambulance than younger persons [17, 24-26] and that older adults disproportionately rely on ambulances to transport them to the ED [27], supporting our results.

In addition, in the present study, patients $\leq 15$ years and those aged $16-64$ years were the most common users of the AHHC service. Other studies have reported similar findings. For example, in Greece, a 10-year longitudinal study showed a gradual increase in the proportion of patients $>75$ years using a private AHHC service [4]; a private AHHC medical service in the US reported that $>90 \%$ of the patients using the AHHC were $<75$ years [28]; and new, unadvertised after-hours units in the UK have also reported similar results [29]. While public AHHC services have existed for a long time in France, approximately $30 \%$ of their clients are children $<15$ years and only $16 \%$ are $>65$ years [30]. These findings suggest that the use of private AHHC services may demonstrate a delayed uptake because the patients are required to search the internet for the information necessary to contact the service. In Japan, a 2014 government white paper reported that the proportion of individuals aged 20-59 years who used the internet was $>91 \%$, but this proportion declined sharply among people aged $>60$ years; the proportion of internet users who were $>75$ years was $<50 \%$ [31]. Thus, as a society ages and the number of older adults with internet access increases, the availability of AHHC services may curtail ED visits and ambulance use. Moreover, as in other countries, if Japan's AHHC services are integrated into the public emergency call services and the operators are able to request $\mathrm{AHHC}$ services, the ability of $\mathrm{AHHC}$ services to effectively reduce $\mathrm{ED}$ visits and ambulance calls may be faster.

\section{Behavior Within Three Days of Using AHHC Services}

We found that the proportions of patients visiting an ED and calling an ambulance after using the AHHC medical service were higher among those with severe conditions and among those who had originally planned to visit an ED or call an ambulance. Several studies targeting patients who called an ambulance have reported that the patients who felt high levels of urgency would call an ambulance even for minor illnesses [32]. Therefore, 
anxious patients may visit an ED or call an ambulance even after using an AHHC service. In contrast, we found that $40 \%$ of patients classified as severely ill would have elected to remain at home, or waited until their hospital was open before seeking consultation, if the AHHC medical service had not been available. This suggests that AHHC services may provide interventions before illness severity becomes too severe. To prove this hypothesis, a survey should be carried out for patients with severe conditions who used an ambulance, and to see whether they would use the AHHC service if it were provided.

\section{Limitations}

There were some limitations to the current study. First, our study involved only a single AHHC medical service. However, this AHHC service provides more than 18,000 nightly visits annually and is the largest after-hours emergency service in Japan. Second, prior to dispatching an AHHC physician, all AHHC service providers provide telephone triage to determine whether immediate ambulance attendance is required, which may cause a selection bias. Third, the response rate for the questionnaire part of the study was relatively low; thus, this study may have a potential sample selection bias. Finally, while the AHHC reduced the number of patients who had originally planned to visit an ED, patients who planned to stay at home and wait for a consultation until a hospital opened may have used the AHHC service because it was available. Therefore, cost-effectiveness analysis will be needed in the future.

\section{Conclusions}

The current study supports previously published work indicating the benefits of AHHC medical services for curtailing ED visits and ambulance use. Further, the study indicates that increasing AHHC medical services awareness among older adults and increasing the use of AHHC services for revisiting patients with severe illnesses, after an initial AHHC service visit, may reduce ED visits and ambulance use. In addition, AHHCs may be useful for providing assistance before an illness becomes severe. Our findings may be helpful in driving government policy, especially for countries facing an aging society.

\section{Abbreviations}

after-hour house call (AHHC), emergency department (ED), interquartile range (IQR), out-of-hours service $(\mathrm{OOH})$

\section{Declarations}

\section{Funding}

This work was supported by grants from Fast Doctor Ltd.

\section{Consent for publication}

Not applicable [individual-level data not included]. 


\section{Acknowledgements}

Not applicable.

\section{Contributions}

R.I., K.M., X.J., and N.T. conceived the study. R.I. performed statistical analyses and wrote the first draft of this study. K.M., X.J., M.I., and N.T. critically reviewed the manuscript. All authors contributed to the design, interpretation of results, and critical revision of the article for intellectually important content.

\section{Ethics declarations}

\section{Ethics approval and consent to participate}

The Research Ethics Committee of University of Tsukuba approved this study (approval number: 1527) and waived informed consent. All methods were performed in accordance with the relevant guidelines and regulations.

\section{Availability of data and material}

The datasets used and/or analyzed during the current study available from the corresponding author on reasonable request.

\section{Competing interests}

1) Rl's joint appointment as an associate professor and 2) KM's XJ's appointment as an assistant professor at the University of Tsukuba were sponsored by Fast DOCTOR Ltd. from October 2019 to the present. Fast DOCTOR Ltd. had no role in conducting this study. I.M. and N.T. have no conflict of interest.

\section{References}

1. Morley C, Unwin M, Peterson GM, Stankovich J, Kinsman L: Emergency department crowding: A systematic review of causes, consequences and solutions. PLoS One 2018, 13(8):e0203316.

2. Yarmohammadian MH, Rezaei F, Haghshenas A, Tavakoli N: Overcrowding in emergency departments: $A$ review of strategies to decrease future challenges. J Res Med Sci 2017, 22:23.

3. Foster H, Moffat KR, Burns N, Gannon M, Macdonald S, O'Donnell CA: What do we know about demand, use and outcomes in primary care out-of-hours services? A systematic scoping review of international literature. BMJ Open 2020, 10(1):e033481.

4. Theocharis G, Barbas SG, Spiropoulos T, Stamouli PE, Perdikis DN, Falagas ME: Patient house calls in Attica and Thessaloniki, Greece (2005-2015): a model for out-of-hospital multispecialty emergency medicine. BMC Health Serv Res 2018, 18(1):304. 
5. Theocharis G, Kechagias KS, Oikonomou M, Chorepsima S, Rodis D, Salpigktis I, Falagas ME: A Model for Out-of-Hospital Multispecialty Emergency Medicine: Accomplishments and Challenges. Health Serv Insights 2018, 11:1178632918805996.

6. Colombo A, Bert F, Camussi E, Gualano MR, Arensi D, Castaldo D, Siliquini R, Pirola ME: Analysis of users and reasons for use of a physician-on-call service in an Italian local health unit. Fam Pract 2016, 33(6):684689.

7. Allen AR, Turbitt $E$, Freed GL: Use of home visiting GP services by paediatric patients presenting at emergency departments. Aust Fam Physician 2016, 45(4):230-235.

8. Ruiz S, Snyder LP, Rotondo C, Cross-Barnet C, Colligan EM, Giuriceo K: Innovative Home Visit Models Associated With Reductions In Costs, Hospitalizations, And Emergency Department Use. Health Aff (Millwood) 2017, 36(3):425-432.

9. Sakurai A, Morimura N, Takeda M, Miura K, Kiyotake N, Ishihara T, Aruga T: A retrospective quality assessment of the 7119 call triage system in Tokyo - telephone triage for non-ambulance cases. J Telemed Telecare 2014, 20(5):233-238.

10. Fire and Disaster Management Agency. Current status of emergency and rescue services. https://www.fdma.go.jp/pressrelease/houdou/items/c941509de3f85432709ea0d63bf23744756cd4a5.pdf. (Accessed on January 22, 2021)

11. Fire and Disaster Management Agency. White Paper on Fire Service. https://www.fdma.go.jp/publication/hakusho/r1/items/r1_all.pdf. (Accessed on January 22, 2021)

12. Yamashita $H$, Koga $H$, Yano K, Taki K, Shima H: The problem and the strategy of increased emergency transport in the geriatric emergency medicine: Especially about charged ambulance: $J$ Jpn Soc Emer Med 2016,19(1):1-6

13. Sakamoto. H, Rahman. M, Nomura. S, Okamoto. E, Koike. S, Yasunaga. H, Kawakami. N, Hashimoto. H, Kondo. N, Abe. SK et al: Japan Health System Review. Vol. 8 No. 1.

14. Inokuchi R, Sato H, Nakajima S, Shinohara K, Nakamura K, Gunshin M, Hiruma T, Ishii T, Matsubara T, Kitsuta $Y$ et al: Development of information systems and clinical decision support systems for emergency departments: a long road ahead for Japan. Emerg Med J 2013, 30(11):914-7.

15. Inokuchi R, Sato H, Nakamura K, Aoki Y, Shinohara K, Gunshin M, Matsubara T, Kitsuta Y, Yahagi N, Nakajima S: Motivations and barriers to implementing electronic health records and ED information systems in Japan. Am J Emerg Med 2014, 32(7):725-730.

16. Otsuki H, Murakami Y, Fujino K, Matsumura K, Eguchi Y: Analysis of seasonal differences in emergency department attendance in Shiga Prefecture, Japan between 2007 and 2010. Acute Med Surg 2016, 3(2):7480.

17. Kawakami C, Ohshige K, Kubota K, Tochikubo O: Influence of socioeconomic factors on medically unnecessary ambulance calls. BMC Health Serv Res 2007, 7:120.

18. Moll van Charante EP, van Steenwijk-Opdam PC, Bindels PJ: Out-of-hours demand for GP care and emergency services: patients' choices and referrals by general practitioners and ambulance services. $B M C$ Fam Pract 2007, 8:46.

19. Ifediora CO, Rogers GD: Continuity of care in after-hours house call medical services: An exploration of follow-up patterns in an Australian context. J Eval Clin Pract 2018, 24(3):514-520. 
20. Buckley DJ, Curtis PW, McGirr JG: The effect of a general practice after-hours clinic on emergency department presentations: a regression time series analysis. Med J Aust 2010, 192(8):448-451.

21. Jones D, Carroll L, Frank L: After-hours care in suburban Canada: influencing emergency department utilization. J Prim Care Community Health 2011, 2(4):250-254.

22. O'Malley AS: After-hours access to primary care practices linked with lower emergency department use and less unmet medical need. Health Aff (Millwood) 2013, 32(1):175-183.

23. van Uden CJ, Crebolder HF: Does setting up out of hours primary care cooperatives outside a hospital reduce demand for emergency care? Emerg Med J 2004, 21(6):722-723.

24. Yazaki H, Nishiura H: Ambulance Transport of Patients with Mild Conditions in Hokkaido, Japan. Int J Environ Res Public Health 2020, 17(3).

25. Platts-Mills TF, Leacock B, Cabañas JG, Shofer FS, McLean SA: Emergency medical services use by the elderly: analysis of a statewide database. Prehosp Emerg Care 2010, 14(3):329-333.

26. Tokuda Y, Abe T, Ishimatsu S, Hinohara S: Ambulance transport of the oldest old in Tokyo: a populationbased study. J Epidemiol 2010, 20(6):468-472.

27. Squire BT, Tamayo A, Tamayo-Sarver JH: At-risk populations and the critically ill rely disproportionately on ambulance transport to emergency departments. Ann Emerg Med 2010, 56(4):341-347.

28. Fortin Ensign S, Baca-Motes K, Steinhubl SR, Topol EJ: Characteristics of the modern-day physician house call. Medicine (Baltimore) 2019, 98(8):e14671.

29. Kelly SJ, Piercy H, Ibbotson R, Fowler Davis SV: Who attends out-of-hours general practice appointments? Analysis of a patient cohort accessing new out-of-hours units. BMJ Open 2018, 8(6):e020308.

30. Meurice L, Chapon T, Chemin F, Gourinchas L, Sauvagnac S, Uijttewaal S, Vandentorren S: General Practitioner House Call Network (SOS Médecins): An Essential Tool for Syndromic Surveillance - Bordeaux, France. Prehosp Disaster Med 2020, 35(3):326-330.

31. Ministry of Internal Affairs and Communications. White paper. The information and communications in Japan. [http://www.soumu.go.jp/johotsusintokei/whitepaper/ja/h26/pdf/n5300000.pdf] (Accessed on January 22, 2021)

32. Dejean D, Giacomini M, Welsford M, Schwartz L, Decicca P: Inappropriate Ambulance Use: A Qualitative Study of Paramedics' Views. Healthc Policy 2016, 11(3):67-79.

\section{Supplementary Files}

This is a list of supplementary files associated with this preprint. Click to download.

- R9.1supple.docx 